International Journal of Innovative Studies in Aquatic Biology and Fisheries

Volume 5, Issue 4, 2019, PP 36-41

ISSN 2454-7662 (Print) \& ISSN 2454-7670 (Online)

DOI: http://dx.doi.org/10.20431/2454-7670.0504007

www.arcjournals.org

\title{
Mathematical Analysis of Morphometric Attributes Effects on Body Weight of Three-Month-Old Lates Calcarifer
}

\author{
YANG Rui ${ }^{1,2}$, ZHAO Wang ${ }^{1,2}$, YU Gang ${ }^{1,2}$, MA Zhenhua ${ }^{1,2^{*}}$ \\ ${ }^{1}$ Sanya Tropical Fisheries Research Institute, Sanya 572018, China. \\ ${ }^{2}$ Tropical Fisheries Research and Development Center, South China Sea Fisheries Research Institute, Chinese \\ Academy of Fishery Sciences, Sanya 572018, China.
}

*Corresponding Author: MA Zhenhua, Tropical Fisheries Research and Development Center, South China Sea Fisheries Research Institute, Chinese Academy of Fishery Sciences, Sanya 572018, China.

\begin{abstract}
The relationship between morphometric attributes and body weight of Lates calcarifer was analyzed using body weight $(Y)$ and 20 morphometric attributes (x1-x20) from three-month-old L. calcarifer. The results show that significant positive correlation between morphometric attributes and body weight, and all the correlation coefficients reach extremely significant level $(P<0.01)$. The path analysis reveal that $x 16$ display the highest positive direct effect (0.635) to body weight, and follow by $x 4, x 2, x 7$ and $x 9, x 1$ affect body weight indirectly by $x 16, x 4, x 2$ and $x 7$; The analysis results of determination coefficients show that the total decision coefficient of six morphological attributes to body weight is find to be 0.976, and indicating those morphological attributes are the main factor to body weight; The multiple regression equation is established by multiple regression analysis. The study shows that the regression equation can be applied to the breeding of $L$. calcarifer.
\end{abstract}

Keywords: Lates calcarifer; Morphometric attributes; Body weight; Path analysis; Multiple regression analysis.

\section{INTRODUCTION}

Lates calcarifer is also known as Asian seabass or 'Barramundi' or giant sea perchan, and it is an important euryhaline carnivorous fish. It can be cultured in both brackish and freshwater ponds as well as in cages (Shanmugaarasu, Kathiresan, Ilanchelian \& Rajendran, 2018). Such as Lates calcarifer is increasingly significant tropical aquaculture species of the Indo-Pacific region and has been cultured for over 30 years in Southeast Asia (Yue, Li, Chao, Chou \& Orban, 2002). And now Lates calcarifer is also an important commercial fish in China, especially the southeast coast. At present, the research on Lates calcariferis was mainly focused on cultivation, nutrition, immunity, physiology, disease, genetics and so on (ATHAUDA \& ANDERSON, 2014; DOMINGOS, ZENGER \& ERRY, 2015; Lin, Yan, Rui-rong, Yang \& Xue-peng, 2015; RANJAN, PRASAD \& VANI, 2014; TRUJILLO-GONZÁLEZ, JOHNSON L \& CONSTANTINOIU, 2015). However, the relationship between morphometric attributes and body weight is one of the basic characteristics for its thoroughbred breeding but rarely reported. Multivariate analysis is one of the main ways to determine the relationship between morphological traits, and it has been widely used in aquatic breeding, for example Pelodiscus sinensis(Fengfan, Wei, Xinping \& Jian, 2015), Exopalaemon carinicauda(Chengsong, Fuhua \& Jianhai, 2013), Orithyia sinica(Shou-Min, Ren-Jie \& Ling-Xu, 2015), Synodus macrops(Jiayu, Wenqi, Yangjie, Qinyu \& Jian, 2013), Pinctada fucata and so on(Caigang, Baosuo \& Dongling, 2015).

In this study, the relationship between morphological traits and body weight of 3-month-old Lates calcarifer was analyzed by multiple regression analysis. In the first place first the main influencing traits of body weight were found by correlation analysis and path analysis. Finally the regression equation of 3month-old Lates calcarifer was established. 
Mathematical Analysis of Morphometric Attributes Effects on Body Weight of Three-Month-Old Lates Calcarifer

\section{MATERIALS AND METHODS}

\subsection{Materials}

A total of 150 individuals of three-month-old Lates calcarifer selected from over $20000 \mathrm{~F} 1$ individuals randomly in Tropical Fisheries Research and Development Center in Sanya China. And all the individuals were cultured in gfiberglass (Model : GBL-TK20-10, specification: $\Phi 200 \times 100 \mathrm{~cm}$ ) of this center with a density of about $150 \mathrm{fish} / \mathrm{m} 3$ with a daily exchange rate of $200 \%$ tank volume. The temperature was maintained from $25^{\circ} \mathrm{Cto} 32^{\circ} \mathrm{C}$, salinity was maintained at $30 \pm 5 \%$, the range of $\mathrm{pH}$ was $7.5 \sim 8.5$ and the $\mathrm{DO} \geq 5 \mathrm{mg} / \mathrm{L}$. The individuals were fed twice a day at $8: 30$ and 17:30 by pellets of common marine fish feed.

\subsection{Measurement Methods}

In this study, morphometric indexes were measured by using a digital vernier caliper (Hangzhou) accurate to $0.01 \mathrm{~mm}$ and an electronic balance which the precision is $0.01 \mathrm{~g}$. The morphometric indexes including body weight(y); body length(x1); body width(x2); head length(x3); stem length(x4); body height(x5); eye diameter(x6); eye distance $(x 7)$; snout length $(x 8)$; the caudal peduncle height $(x 9)$; the caudal peduncle length(x10); the distance of the origin of the first dorsal fin to the end of the second dorsal fin(x11); the distance of the origin of the first dorsal fin to the base of pectoral fin(x12); the distance of the origin of the first dorsal fin to the base of pelvic fin(x13); the distance of the origin of the first dorsal fin to the origin of anal fin(x14); the distance of the end of the origin of anal fin to the second dorsal fin(x15); the distance of the base of pectoral fin to the end of the second dorsal fin(x16); the distance of the base of pelvic fin to the end of the second dorsal fin(x17); the distance of the origin of anal fin to the base of pelvic fin(x18); the origin of the anal fin to the base of the pectoral fin(x19); the base of the pectoral fin to the base of pelvic fin( $\mathrm{x} 20)$.

\subsection{Analysis}

Statistical analyses were performed with SPSS 19.0 software(SPSS Inc., Chicago, USA). The descriptive statistical results of each trait were obtained in the first place, and then the direct and indirect effects of morphological traits and the body weight were determined by correlation analysis and path analysis. Finally, multiple regression equation of 3-month-old L. calcarifer is established by multiple regression analysis.

\section{RESUltS}

\subsection{The Descriptive Statistic Of Morphometric Attributes Of Three-Month-Old L. Calcarifer}

In this study, the descriptive statistic of morphometric attributes of three-month-old L. calcarifer were showed in Tab.1.The body weight three-month-old L. calcarifer was between 13.17 and $93.46 \mathrm{~g}$, while the average was $30.18 \mathrm{~g}$. The highest value of body length was $86.95 \mathrm{~mm}$ and lowest was $167.90 \mathrm{~mm}$, their average was $113.52 \mathrm{~mm}$. The highest CVs of all measured traits was body weight (43.81\%), it indicated that the body weight had a large selection potential in the traits of 3-month-old L. calcarifer.

Table1. The descriptive statistic of morphometric attributes of three-month-old L. calcarifer

\begin{tabular}{|c|c|c|c|c|c|c|}
\hline Traits & Mean & SD & SE & Kurtosis & Skewness & CV\% \\
\hline $\boldsymbol{y} / \mathbf{g}$ & 30.18 & 13.22 & 1.08 & 4.53 & 1.65 & 43.81 \\
\hline $\boldsymbol{x}_{\mathbf{1}} / \mathbf{m m}$ & 113.52 & 16.46 & 1.34 & 0.28 & 0.56 & 14.50 \\
\hline $\boldsymbol{x}_{\mathbf{2}} / \mathbf{m m}$ & 14.79 & 2.27 & 0.18 & 0.82 & 0.69 & 15.31 \\
\hline $\boldsymbol{x}_{\mathbf{3}} / \mathbf{m m}$ & 37.32 & 5.46 & 0.45 & 0.53 & 0.62 & 14.62 \\
\hline $\boldsymbol{x}_{\mathbf{4}} / \mathbf{m m}$ & 45.97 & 7.12 & 0.58 & 1.27 & 0.78 & 15.48 \\
\hline $\boldsymbol{x}_{\mathbf{5}} / \mathbf{m m}$ & 34.88 & 4.69 & 0.38 & -0.30 & 0.34 & 13.44 \\
\hline $\boldsymbol{x}_{\mathbf{6}} / \mathbf{m m}$ & 6.70 & 0.56 & 0.05 & 0.46 & 0.17 & 8.43 \\
\hline $\boldsymbol{x}_{\mathbf{7}} / \mathbf{m m}$ & 12.04 & 1.28 & 0.10 & 1.48 & 1.03 & 10.63 \\
\hline $\boldsymbol{x}_{\mathbf{8}} / \mathbf{m m}$ & 6.55 & 0.99 & 0.08 & 1.08 & 0.56 & 15.13 \\
\hline $\boldsymbol{x}_{\mathbf{9}} / \mathbf{m m}$ & 17.77 & 2.83 & 0.23 & 0.46 & 0.51 & 15.92 \\
\hline
\end{tabular}

International Journal of Innovative Studies in Aquatic Biology and Fisheries (IJISABF)

Page | 37 
Mathematical Analysis of Morphometric Attributes Effects on Body Weight of Three-Month-Old Lates Calcarifer

\begin{tabular}{|c|c|c|c|c|c|c|}
\hline$x_{10} / \mathrm{mm}$ & 26.80 & 4.43 & 0.36 & 0.74 & 0.67 & 16.52 \\
\hline$x_{11} / \mathrm{mm}$ & 44.10 & 6.81 & 0.56 & 1.52 & 0.88 & 15.43 \\
\hline$x_{12} / \mathrm{mm}$ & 25.21 & 3.64 & 0.30 & -0.21 & 0.42 & 14.43 \\
\hline$x_{13} / \mathrm{mm}$ & 36.09 & 4.98 & 0.41 & -0.24 & 0.38 & 13.80 \\
\hline$x_{14} / \mathrm{mm}$ & 47.87 & 6.94 & 0.57 & 0.84 & 0.70 & 14.50 \\
\hline$x_{15} / \mathrm{mm}$ & 24.06 & 3.57 & 0.29 & 1.37 & 0.76 & 14.84 \\
\hline$x_{16} / \mathrm{mm}$ & 55.31 & 8.61 & 0.70 & 0.79 & 0.76 & 15.57 \\
\hline$x_{17} / \mathrm{mm}$ & 57.10 & 9.75 & 0.80 & 5.18 & -0.49 & 17.07 \\
\hline$x_{18} / \mathrm{mm}$ & 44.06 & 7.10 & 0.58 & 0.59 & 0.63 & 16.12 \\
\hline$x_{19} / \mathrm{mm}$ & 47.09 & 7.50 & 0.61 & 0.85 & 0.71 & 15.93 \\
\hline$x_{20} / \mathrm{mm}$ & 12.81 & 1.89 & 0.15 & 0.86 & 0.56 & 14.74 \\
\hline
\end{tabular}

\subsection{Correlation Coefficients Among Morphometric Attributes Of Three-Month-Old L. Calcarifer}

The correlation between the morphological traits of the of three-month-old L. calcarifer was highly significant (Tab.2). The correlation coefficients of $\boldsymbol{x}_{5}$ and $\boldsymbol{x}_{13}$ was the largest (0.984), however, x6 and x8 was on the contrary the numerical value was only 0.565 . It also showed another message that, the largest contribution to body weight of three-month-old L. calcarifer was x16 (0.968), and the second was x11 (0.957), the last was x6 (0.713).

Table2. Correlation coefficients among morphometric attributes of three-month-old L. calcarifer

\begin{tabular}{|c|c|c|c|c|c|c|c|c|c|c|c|c|c|c|c|c|c|c|c|c|}
\hline $\begin{array}{c}\text { Trai } \\
\text { ts }\end{array}$ & $y$ & $x_{1}$ & $x_{2}$ & $x_{3}$ & $x_{4}$ & $x_{5}$ & $x_{6}$ & $x_{7}$ & $x_{8}$ & $x_{9}$ & $x_{10}$ & $x_{11}$ & $x_{12}$ & $x_{13}$ & $x_{14}$ & $x_{15}$ & $x_{16}$ & $x_{17}$ & $x_{18}$ & $x_{19}$ \\
\hline$x_{1}$ & $\begin{array}{c}0.95 \\
0^{* *}\end{array}$ & & & & & & & & & & & & & & & & & & & \\
\hline$x_{2}$ & $\begin{array}{c}0.93 \\
7^{* *}\end{array}$ & $\begin{array}{c}0.90 \\
6^{* *}\end{array}$ & & & & & & & & & & & & & & & & & & \\
\hline$x_{3}$ & $\begin{array}{c}0.91 \\
6^{* *} \\
\end{array}$ & \begin{tabular}{|c|}
0.96 \\
$1^{* * *}$ \\
\end{tabular} & \begin{tabular}{|c}
0.86 \\
$9^{* * *}$ \\
\end{tabular} & & & & & & & & & & & & & & & & & \\
\hline$x_{4}$ & $\begin{array}{c}0.93 \\
1^{* *} \\
\end{array}$ & $\begin{array}{c}0.93 \\
2^{* *}\end{array}$ & $\begin{array}{c}0.87 \\
8^{* *}\end{array}$ & $\begin{array}{c}0.87 \\
4^{* *}\end{array}$ & & & & & & & & & & & & & & & & \\
\hline$x_{5}$ & $\begin{array}{c}0.94 \\
3^{* *}\end{array}$ & $\begin{array}{c}0.95 \\
8^{* *}\end{array}$ & $\begin{array}{c}0.92 \\
4^{* *}\end{array}$ & $\begin{array}{c}0.93 \\
2^{* *}\end{array}$ & $\begin{array}{c}0.91 \\
1^{* *}\end{array}$ & & & & & & & & & & & & & & & \\
\hline$x_{6}$ & $\begin{array}{c}0.71 \\
3^{* *} \\
\end{array}$ & \begin{tabular}{|c|}
0.76 \\
$4^{* *}$ \\
\end{tabular} & \begin{tabular}{|c|}
0.64 \\
$3^{* *}$ \\
\end{tabular} & \begin{tabular}{|c|}
0.77 \\
$0^{* *}$ \\
\end{tabular} & $\begin{array}{c}0.71 \\
2^{* *}\end{array}$ & \begin{tabular}{|c|}
0.72 \\
$4^{* * *}$ \\
\end{tabular} & & & & & & & & & & & & & & \\
\hline$x_{7}$ & $\begin{array}{c}0.94 \\
0^{* *}\end{array}$ & $\begin{array}{c}0.92 \\
5^{* * *}\end{array}$ & $\begin{array}{c}0.89 \\
2^{* * *}\end{array}$ & $\begin{array}{c}0.89 \\
5^{* *}\end{array}$ & $\begin{array}{c}0.88 \\
5^{* *}\end{array}$ & $\begin{array}{c}0.89 \\
8^{* * *}\end{array}$ & $\begin{array}{c}0.72 \\
0^{* *}\end{array}$ & & & & & & & & & & & & & \\
\hline$x_{8}$ & $\begin{array}{c}0.75 \\
7^{* *}\end{array}$ & $\begin{array}{c}0.79 \\
9^{* *} \\
\end{array}$ & $\begin{array}{c}0.71 \\
3^{* *}\end{array}$ & $\begin{array}{c}0.84 \\
3^{* *}\end{array}$ & $\begin{array}{c}0.77 \\
4^{* *}\end{array}$ & $\begin{array}{c}0.78 \\
0 * *\end{array}$ & $\begin{array}{c}0.56 \\
5^{* *}\end{array}$ & $\begin{array}{c}0.70 \\
5^{* *}\end{array}$ & & & & & & & & & & & & \\
\hline$x_{9}$ & $\begin{array}{c}0.87 \\
9^{* *}\end{array}$ & $\begin{array}{c}0.88 \\
2^{* *}\end{array}$ & $\begin{array}{c}0.83 \\
9^{* * *}\end{array}$ & $\begin{array}{c}0.86 \\
6 * *\end{array}$ & $\begin{array}{c}0.86 \\
5^{* *}\end{array}$ & $\begin{array}{l}0.90 \\
6\end{array}$ & $\begin{array}{c}0.68 \\
8^{* * *}\end{array}$ & $\begin{array}{c}0.81 \\
7^{* *}\end{array}$ & $\begin{array}{c}0.78 \\
6^{* *}\end{array}$ & & & & & & & & & & & \\
\hline$x_{10}$ & \begin{tabular}{|c}
0.87 \\
$7^{* *}$ \\
\end{tabular} & $\begin{array}{c}0.88 \\
4^{* *} \\
\end{array}$ & \begin{tabular}{|c}
0.85 \\
$8^{* *}$ \\
\end{tabular} & \begin{tabular}{|c|c}
0.83 \\
$8^{* *}$ \\
\end{tabular} & $\begin{array}{c}0.78 \\
8^{* *}\end{array}$ & $\begin{array}{c}0.87 \\
3^{* *}\end{array}$ & $\begin{array}{c}0.68 \\
7^{* *}\end{array}$ & $\begin{array}{c}0.85 \\
7^{* * *}\end{array}$ & \begin{tabular}{|c|}
0.63 \\
$2^{* *}$ \\
\end{tabular} & \begin{tabular}{|c|}
0.83 \\
$0 * *$ \\
\end{tabular} & & & & & & & & & & \\
\hline$x_{11}$ & $\begin{array}{c}0.95 \\
7^{* * *} \\
\end{array}$ & $\begin{array}{c}0.95 \\
9^{* *} \\
\end{array}$ & $\begin{array}{c}0.90 \\
7^{* * *} \\
\end{array}$ & $\begin{array}{c}0.92 \\
7^{* *} \\
\end{array}$ & $\begin{array}{c}0.90 \\
3^{* *} \\
\end{array}$ & $\begin{array}{c}0.93 \\
9^{* * *} \\
\end{array}$ & $\begin{array}{c}0.72 \\
2^{* *}\end{array}$ & \begin{tabular}{|c|}
0.92 \\
$4^{* * *}$ \\
\end{tabular} & \begin{tabular}{|c|}
0.72 \\
$6^{* * *}$ \\
\end{tabular} & \begin{tabular}{|c|}
0.84 \\
$6^{* *}$ \\
\end{tabular} & \begin{tabular}{|c}
0.87 \\
$9^{* *}$ \\
\end{tabular} & & & & & & & & & \\
\hline$x_{12}$ & $\begin{array}{c}0.90 \\
2^{* *}\end{array}$ & $\begin{array}{c}0.94 \\
5^{* *}\end{array}$ & $\begin{array}{c}0.87 \\
7^{* *}\end{array}$ & $\begin{array}{c}0.91 \\
7^{* *}\end{array}$ & $\begin{array}{c}0.89 \\
7^{* *}\end{array}$ & $\begin{array}{c}0.94 \\
9^{* *}\end{array}$ & $\begin{array}{c}0.73 \\
1^{* *}\end{array}$ & $\begin{array}{c}0.86 \\
9^{* *}\end{array}$ & $\begin{array}{c}0.76 \\
1^{* *}\end{array}$ & $\begin{array}{c}0.86 \\
6 * *\end{array}$ & $\begin{array}{c}0.84 \\
1^{* *}\end{array}$ & $\begin{array}{c}0.87 \\
1^{* *}\end{array}$ & & & & & & & & \\
\hline$x_{13}$ & $\begin{array}{c}0.93 \\
5^{* *}\end{array}$ & $\begin{array}{c}0.96 \\
4^{* *}\end{array}$ & $\begin{array}{c}0.90 \\
8^{* *}\end{array}$ & $\begin{array}{c}0.94 \\
2^{* *}\end{array}$ & $\begin{array}{c}0.90 \\
9^{* *}\end{array}$ & $\begin{array}{c}0.98 \\
4^{* *}\end{array}$ & $\begin{array}{c}0.74 \\
7^{* *}\end{array}$ & $\begin{array}{c}0.88 \\
9^{* * *}\end{array}$ & $\begin{array}{c}0.80 \\
6^{* *}\end{array}$ & $\begin{array}{c}0.90 \\
6 * *\end{array}$ & $\begin{array}{c}0.86 \\
6^{* *}\end{array}$ & $\begin{array}{c}0.92 \\
1^{* * *}\end{array}$ & $\begin{array}{c}0.96 \\
9^{* *}\end{array}$ & & & & & & & \\
\hline$x_{14}$ & \begin{tabular}{|l}
0.95 \\
$4^{* *}$ \\
\end{tabular} & $\begin{array}{c}0.96 \\
2^{* *} \\
\end{array}$ & \begin{tabular}{|c|}
0.90 \\
$4^{* * *}$ \\
\end{tabular} & \begin{tabular}{|c|}
0.93 \\
$8^{* *}$ \\
\end{tabular} & $\begin{array}{c}0.94 \\
7^{\text {** }}\end{array}$ & $\begin{array}{c}0.95 \\
6^{* *}\end{array}$ & $\begin{array}{c}0.73 \\
7^{* *}\end{array}$ & \begin{tabular}{|c|}
0.91 \\
$3^{* *}$ \\
\end{tabular} & \begin{tabular}{|c|}
0.77 \\
$8^{* *}$ \\
\end{tabular} & \begin{tabular}{|c|}
0.88 \\
$2^{* *}$ \\
\end{tabular} & \begin{tabular}{|c|}
0.82 \\
$2^{* *}$
\end{tabular} & \begin{tabular}{|c|}
0.97 \\
$2^{* *}$
\end{tabular} & $\begin{array}{c}0.90 \\
3^{* *}\end{array}$ & $\begin{array}{c}0.94 \\
3^{* *}\end{array}$ & & & & & & \\
\hline$x_{15}$ & $\begin{array}{c}0.94 \\
4^{* *}\end{array}$ & $\begin{array}{c}0.93 \\
8^{* *}\end{array}$ & $\begin{array}{c}0.91 \\
4^{* *}\end{array}$ & $\begin{array}{c}0.89 \\
3^{* *}\end{array}$ & $\begin{array}{c}0.86 \\
5^{* * *}\end{array}$ & $\begin{array}{c}0.94 \\
9^{* *}\end{array}$ & $\begin{array}{c}0.70 \\
5^{* *}\end{array}$ & $\begin{array}{c}0.90 \\
2^{* *}\end{array}$ & $\begin{array}{c}0.69 \\
8^{* *}\end{array}$ & $\begin{array}{c}0.84 \\
7^{* *}\end{array}$ & $\begin{array}{c}0.92 \\
9^{* *}\end{array}$ & $\begin{array}{c}0.95 \\
3^{* *}\end{array}$ & $\begin{array}{c}0.89 \\
4^{* *}\end{array}$ & $\begin{array}{c}0.93 \\
3^{* *}\end{array}$ & $\begin{array}{c}0.91 \\
9^{* *}\end{array}$ & & & & & \\
\hline$x_{16}$ & $\begin{array}{c}0.96 \\
8^{* *}\end{array}$ & $\begin{array}{c}0.97 \\
9^{* *}\end{array}$ & $\begin{array}{c}0.92 \\
1^{* * *}\end{array}$ & $\begin{array}{c}0.93 \\
4^{* *}\end{array}$ & $\begin{array}{c}0.93 \\
2^{* *}\end{array}$ & $\begin{array}{c}0.96 \\
3^{* * *}\end{array}$ & $\begin{array}{c}0.74 \\
8^{* *}\end{array}$ & $\begin{array}{c}0.93 \\
4^{* *}\end{array}$ & $\begin{array}{c}0.73 \\
3^{* *}\end{array}$ & $\begin{array}{c}0.86 \\
9^{* *}\end{array}$ & $\begin{array}{c}0.90 \\
1^{* *}\end{array}$ & $\begin{array}{c}0.97 \\
5^{* *}\end{array}$ & $\begin{array}{c}0.94 \\
2^{* *}\end{array}$ & $\begin{array}{c}0.96 \\
0^{* *}\end{array}$ & $\begin{array}{c}0.96 \\
5^{* *}\end{array}$ & $\begin{array}{c}0.96 \\
3^{* * *}\end{array}$ & & & & \\
\hline$x_{17}$ & $\begin{array}{c}0.88 \\
7^{* *}\end{array}$ & $\begin{array}{c}0.90 \\
9^{* *}\end{array}$ & $\begin{array}{c}0.85 \\
5^{* * *}\end{array}$ & $\begin{array}{c}0.88 \\
8^{* *}\end{array}$ & $\begin{array}{c}0.83 \\
9^{* *}\end{array}$ & $\begin{array}{c}0.91 \\
2^{* *}\end{array}$ & $\begin{array}{c}0.69 \\
2^{* *}\end{array}$ & $\begin{array}{c}0.86 \\
2^{* * *}\end{array}$ & $\begin{array}{c}0.70 \\
1^{* *}\end{array}$ & $\begin{array}{c}0.80 \\
9^{* * *}\end{array}$ & $\begin{array}{c}0.83 \\
2^{* *}\end{array}$ & $\begin{array}{c}0.90 \\
9^{* *}\end{array}$ & $\begin{array}{c}0.86 \\
9^{* *}\end{array}$ & $\begin{array}{c}0.91 \\
2^{* *}\end{array}$ & \begin{tabular}{|c|}
0.90 \\
$1^{* * *}$
\end{tabular} & $\begin{array}{c}0.90 \\
3^{* * *}\end{array}$ & $\begin{array}{c}0.91 \\
6^{* *}\end{array}$ & & & \\
\hline
\end{tabular}


Mathematical Analysis of Morphometric Attributes Effects on Body Weight of Three-Month-Old Lates Calcarifer

\begin{tabular}{|l|l|l|l|l|l|l|l|l|l|l|l|l|l|l|l|l|l|l|}
\hline $\boldsymbol{x}_{18}$ & 0.92 & 0.94 & 0.87 & 0.91 & 0.94 & 0.92 & 0.76 & 0.88 & 0.77 & 0.86 & 0.78 & 0.92 & 0.90 & 0.93 & 0.97 & 0.87 & 0.94 & 0.88 \\
\hline
\end{tabular}

\begin{tabular}{|c|c|c|c|c|c|c|c|c|c|c|c|c|c|c|c|c|c|c|c|} 
& $6^{* *}$ & $4^{* *}$ & $7^{* *}$ & $6^{* *}$ & $7^{* * *}$ & $9^{* *}$ & $2^{* *}$ & $5^{* *}$ & $3^{* *}$ & $7^{* *}$ & $9^{* *}$ & $7^{* *}$ & $6^{* *}$ & $7^{* *}$ & $0^{* *}$ & $3^{* *}$ & $8^{* *}$ & $1^{* *}$ & \\
\hline$x_{19}$ & 0.94 & 0.95 & 0.89 & 0.91 & 0.96 & 0.94 & 0.74 & 0.91 & 0.74 & 0.86 & 0.81 & 0.94 & 0.92 & 0.93 & 0.98 & 0.89 & 0.97 & 0.88 & 0.98
\end{tabular}

\begin{tabular}{|c|c|c|c|c|c|c|c|c|c|c|c|c|c|c|c|c|c|c|c|c|c|c|c|}
$x_{19}$ & 0.94 & 0.95 & $8^{* *}$ & $9^{* *}$ & $9^{* * *}$ & $8^{* *}$ & $4^{* *}$ & $2^{* *}$ & $6^{* *}$ & $5^{* *}$ & $8^{* *}$ & $7^{* *}$ & $3^{* *}$ & $4^{* *}$ & $4^{* *}$ & $8^{* *}$ & $1^{* *}$ & $8^{* *}$ & $1^{* *}$ & $0^{* *}$ & $1^{* *}$ \\
\hline
\end{tabular}

\begin{tabular}{|l|l|l|l|l|l|l|l|l|l|l|l|l|l|l|l|l|l|l|l|l|}
\hline $\boldsymbol{x}_{20}$ & 0.89 & 0.88 & 0.87 & 0.83 & 0.86 & 0.92 & 0.63 & 0.85 & 0.70 & 0.83 & 0.83 & 0.88 & 0.83 & 0.90 & 0.89 & 0.90 & 0.90 & 0.84 & 0.85 & 0.89 \\
\hline
\end{tabular}

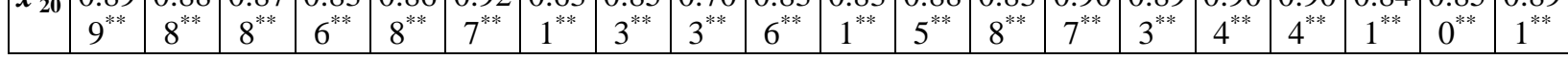

Note: * represents significant correlation $(P<0.05)$, ** represents highly significant correlation $(P<0.01)$.

\subsection{Path Analysis of Morphological Attributes to Body Weight of Three-Month-Old $L$. Calcarifer}

The path analysis of morphological attributes to body weight of three-month-old L. calcarifer were showed in Table 3. To remove all the no significant correlation variables except $\boldsymbol{x}_{1}, \boldsymbol{x}_{2}, \boldsymbol{x}_{4}, \boldsymbol{x}_{7}, \boldsymbol{x}_{9}$ and $\boldsymbol{x}_{16}$ after significant difference testing of the path coefficients. According to the composition of the correlation coefficient, the correlation coefficient between morphological traits and body weight is decomposed into two parts: direct effect and indirect effect. In addition to $\boldsymbol{x}_{16}$, the direct effects of morphological traits on body weight were less than indirect effects. The direct effect of $\boldsymbol{x}_{\mathbf{1 6}}$ on the body weight of three-month-old L. calcarifer was the highest $(0.635)$, which reached the significant level, it indicated that the direct effect of $x_{16}$ on body weight was the largest. The direct effect of $x_{1}$ on body weight is negative, indicating that $\boldsymbol{x}_{\mathbf{1}}$ has a negative effect on body weight; however it produced a large indirect effect through $\boldsymbol{x}_{\mathbf{1 6}}$, with a total indirect effect of 1.277 .

Table3. Path analysis of morphological attributes to body weight of three-month-old L. calcarifer

\begin{tabular}{|c|c|c|c|c|c|c|c|c|c|}
\hline & \multirow{2}{*}{$\begin{array}{c}\text { Correlation } \\
\text { coefficient }\end{array}$} & \multirow{2}{*}{ Direct } & \multicolumn{7}{|c|}{ Indirect } \\
\cline { 4 - 9 } Traitss & & $\Sigma$ & $\boldsymbol{x}_{1}$ & $\boldsymbol{x}_{2}$ & $\boldsymbol{x}_{4}$ & $\boldsymbol{x}_{7}$ & $\boldsymbol{x}_{9}$ & $\boldsymbol{x}_{16}$ \\
\hline $\boldsymbol{x}_{\mathbf{1}}$ & 0.950 & $-0.327^{* *}$ & 1.277 & - & 0.183 & 0.203 & 0.182 & 0.087 & 0.622 \\
\hline $\boldsymbol{x}_{\mathbf{2}}$ & 0.937 & $0.202^{* *}$ & 0.739 & -0.296 & - & 0.191 & 0.176 & 0.083 & 0.585 \\
\hline $\boldsymbol{x}_{\mathbf{4}}$ & 0.931 & $0.218^{* *}$ & 0.724 & -0.305 & 0.177 & - & 0.174 & 0.086 & 0.592 \\
\hline $\boldsymbol{x}_{\mathbf{7}}$ & 0.940 & $0.197^{* *}$ & 0.745 & -0.302 & 0.180 & 0.193 & - & 0.081 & 0.593 \\
\hline $\boldsymbol{x}_{\mathbf{9}}$ & 0.879 & $0.099^{*}$ & 0.782 & -0.288 & 0.169 & 0.189 & 0.161 & - & 0.552 \\
\hline $\boldsymbol{x}_{\mathbf{1 6}}$ & 0.968 & $0.635^{*}$ & 0.339 & -0.320 & 0.186 & 0.203 & 0.184 & 0.086 & - \\
\hline
\end{tabular}

Note: * represents significant correlation $(P<0.05)$, ** represents highly significant correlation $(P<0.01)$.

\subsection{Coefficient of Determination of Morphological Attributes to Body Weight of Three-Month-Old L.Calcarifer}

In this study, the coefficient of determination of morphological attributes to body weight of three-monthold L.calcarifer were showed in Table.4.The results showed that, the sum of the direct decision coefficient and the indirect decision coefficient is 0.976 . The results indicated that $\boldsymbol{x}_{1}, \boldsymbol{x}_{2}, \boldsymbol{x}_{4}, \boldsymbol{x}_{7}, \boldsymbol{x}_{9}$ and $\boldsymbol{x}_{\mathbf{1 6}}$ were the important traits affecting the body weight of three-month-old L.calcarifer, and other traits had little effect on body weight. Table. 4 also demonstrated that the impact of these six traits on the body weight there are differences. $\boldsymbol{x}_{\mathbf{1 6}}$ most directly determined.

Table4. Coefficient of determination of morphological attributes to body weight of three-month-old L. calcarifer

\begin{tabular}{|c|c|c|c|c|c|c|c|}
\hline Traits & $\boldsymbol{x}_{\mathbf{1}}$ & $\boldsymbol{x}_{\mathbf{2}}$ & $\boldsymbol{x}_{\mathbf{4}}$ & $\boldsymbol{x}_{\mathbf{7}}$ & $\boldsymbol{x}_{\mathbf{9}}$ & $\boldsymbol{x}_{\mathbf{1 6}}$ & $\boldsymbol{\Sigma}$ \\
\hline $\boldsymbol{x}_{\mathbf{1}}$ & 0.107 & -0.120 & -0.133 & -0.119 & -0.057 & -0.407 & \\
\hline $\boldsymbol{x}_{\mathbf{2}}$ & & 0.041 & 0.077 & 0.071 & 0.034 & 0.236 \\
\hline $\boldsymbol{x}_{\mathbf{4}}$ & & & 0.048 & 0.076 & 0.037 & 0.258 \\
\hline $\boldsymbol{x}_{\mathbf{7}}$ & & & & 0.039 & 0.032 & 0.234 \\
\hline $\boldsymbol{x}_{\mathbf{9}}$ & & & & 0.010 & 0.109 \\
\hline \multicolumn{2}{|c|}{$\boldsymbol{x}_{\mathbf{1 6}}$} & & & & 0.403 & \\
\end{tabular}

\subsection{Construction of Multiple Regression Equation}

The multiple regression equation of morphological attributes to body weight of three-month-old $L$. calcarifer is established by multiple regression analysis, it is:

International Journal of Innovative Studies in Aquatic Biology and Fisheries (IJISABF) 
$y=-64.974+1.273 x_{2}+0.238 x_{4}+2.205 x_{7}+0.401 x_{9}+0.573 x_{16}$

In the equation, $y$ is body weight, $x_{2}$ is body width; $x_{4}$ is stem length; $x_{7}$ is eye distance; $x_{9}$ is the caudal peduncle height; $x_{16}$ is the distance of the base of pectoral fin to the end of the second dorsal fin. The variance analysis showed that the regression relation of the multiple regression equation is extremely significant $\left(F=705.995, P=0.000<0.01, R^{2}=0.961\right)$. The partial regression coefficient of 5 morphological attributes $\left(x_{2}, x_{4}, x_{7}, x_{9}\right.$ and $\left.x_{16}\right)$ to body weight of three-month-old L.calcarifer are either significant or extremely significant.

\section{DiSCUSSION AND CONCLUSION}

In the reported study of fish path analysis, it has been found that the fish breeding attributes are not the same. This difference is related to the species of fish, gender (An \& Qingeheng, 2012), aquiculture density (Limin, Barry, Chao \& Liping), and the morphological attributes selected by the researchers. It has been choosed that the length of the body (body length, body width, body height, head length, body length and tail length, etc.), eye index (eye diameter, eye distance, etc.) in the study of fish path analysis, and the attributes related to fins are rare. The attributes related to fins $\left(x_{11}-x_{20}\right)$ were added on the basis of the commonly used indexes $\left(x_{1}-x_{10}\right)$ in the study, the results of path analysis showed that the largest direct path coefficient of body weight were the fish fin index $\left(x_{16}\right)$. The regression analysis showed that the total decision coefficient was 0.976, indicating that the fish fin correlation index could also be used as the morphological attributes affecting the body weight. Zhou Shaofeng found that the total length, body length, body height and head length of red spot grouper (E. akaara) body mass of the total coefficient of determination was 0.924(Shao-feng, Wei-qing \& Rui-fa, 2015); and the range of values for other study was 0.784-0.967. However, the correlation index of the study was higher than the above results, it indicated that the fins was also one of the main traits to construct multiple regression equation of L.calcarifer.

Research has also shown that morphological traits affecting the body weight of fish may be related to the growth stage. The results of the study on the relationship between morphological traits and body weight of Paralichthys olivaceus at 20-40 days showed that the main trait that affected body weight at 20 days of age was body height while at other stages the major influencing factor was body length (Xue-hong, Baoming, Huan-li \& Xiao-lan, 2014). The most important morphological traits that affected the body weight of early Pseudosciaena crocea were body height and body length, while full length was important in addition to these two factors in the medium term(Xian-de, Ming-yi, Zhi-yong \& Guang-tai, 2010). Body length or body height was the main traits that affected the body weight of Liza haematocheila at different times.In the study of path analysis of shellfish, including Scapharca subcrenata Lischke,Chlamys nobilis and so on were also confirmed that the traits affect their body weight at different stages were always different. In this study $X_{2}, X_{4} X_{7}, X_{9}$ and $X_{16}$ were related to body weight of three-month-old Lates calcarifer closely. However, the relationship between morphological traits and body weight in other stages will be further research and exploration.

\section{ACKNOWLEDGMENT}

This project was funded by Guangxi Innovation-driven Development Projects (GuikeAA18242031), and Central Public-interest Scientific Institution Basal Research Fund, South China Sea Fisheries Research Institute, CAFS (2017ZD01, 2018ZD01),

\section{REFERENCES}

[1] An, H., \& Qingeheng, Z. (2012). RELATIONSHIP ANALYSIS BETWEEN MORPHOMETRIC ATTRIBUTES AND BODY WEIGHT OF NIBEA COIBOR IN ARAFURA SEA OF INDONESIA. Transaction of Oceanology and Limnology 1, 41-48.

[2] ATHAUDA, S., \& ANDERSON, T. (2014). Effect of temperature and salinity on sex inversion in Asian Seabass (Lates calcarifer): relationship with plasma sex steroids concentration and aromatase activity of gonad and brain. Aquaculture Research 45, 787-797.

[3] Caigang, T., Baosuo, L., \& Dongling, Z. (2015). Analysis of grey relationship between morphological traits and body weight of pearl oyster ( Pinctada fucata) . South China Fisheries Science 2, 35-40.

International Journal of Innovative Studies in Aquatic Biology and Fisheries (IJISABF)

Page | 40 
[4] Chengsong, Z., Fuhua, L., \& Jianhai, X. (2013). Path analysis of effects of morphometric attributes on body weight of Exopalaemon carinicauda. Journal of Fisheries of China 6, 809-815.

[5] DOMINGOS, ZENGER, \& ERRY. (2015). Whole-genome shotgun sequence assembly enables rapid gene characterization in the tropical fish barramundi, Lates calcarifer. Animal Genetics 46, 468-469.

[6] Fengfan, X., Wei, L., Xinping, Z., \& Jian, Z. (2015). Effects of Morphometric Traits on Body Weight of Three Cultured Populations of Pelodiscus sinensis. Genomics and Applied Biology 6, 1247-1253.

[7] Jiayu, T., Wenqi, X., Yangjie, O., Qinyu, C., \& Jian, S. (2013). Correlation and Path Analysis of Morphometric Attributes of Synodus macrops. Chinese Agricultural Science Bulletin 5, 71-75.

[8] Limin, F., Barry, K., Chao, S., \& Liping, Q. Path Analysis for Growth-related Traits of GIFT Strain of Nile Tilapia (Oreochromis niloticus under Different Stocking Densities. Chinese Agricultural Science Bulletin 11, 83-87.

[9] Lin, W., Yan, L., Rui-rong, Q., Yang, X., \& Xue-peng, W. (2015). Diagnosis of Iridovirus Disease in Sea Bass Lates calcarifer. Chinese Journal of Fisheries 4, 28-32.

[10] RANJAN, R., PRASAD, K., \& VANI, T. (2014). Effect of dietary chitosan on haematology, innate immunity and disease resistance of Asian seabass Lates calcarifer (Bloch). Aquaculture Research 45, 983-993.

[11] Shanmugaarasu, V., Kathiresan, K., Ilanchelian, K., \& Rajendran, N. (2018). Survival and growth of fish (Lates calcarifer) under integrated mangrove-aquaculture and open-aquaculture systems. Aquaculture Reports 9, 18-24.

[12] Shao-feng, Z., Wei-qing, H., \& Rui-fa, Z. (2015). Correlation Analysis of Main Morphological Traits with Body Weight of 6 Month Old Redspotted Grouper Epinephelus akaara. Chinese Journal of Fisheries 3, 48-51.

[13] Shou-Min, L., Ren-Jie, W., \& Ling-Xu, J. (2015). PATH ANALYSIS BETWEEN MORPHOLOGICAL CHARACTERS AND BODY WEIGHT OF CHINESE TIGER-HEAD CRAB ORITHYIA SINICA BY MULTIPLE REGRESSION. Oceanologia Et Limnologia Sinica 6, 1438-1443.

[14] TRUJILLO-GONZÁLEZ, A., JOHNSON L, K., \& CONSTANTINOIU, C. (2015). Histopathology associated with haptor attachment of the ectoparasitic monogenean Neobenedenia sp. (Capsalidae) to barramundi, Lates calcarifer (Bloch). 38, 1063-1067.

[15] Xian-de, L., Ming-yi, C., Zhi-yong, W., \& Guang-tai, Z. (2010). Correlation analysis of morphometric traits and body weight of large yellow croaker Pseudosciaena crocea at different growth stage. Journal of Tropical Oceanography 5, 159-163.

[16] Xue-hong, T., Bao-ming, G., Huan-li, W., \& Xiao-lan, Y. (2014). Correlation Between Morphological Traits and Body Weight of Japanese Flounder during Different Periods. Hubei Agricultural Sciences 4, 863-865.

[17] Yue, G.H., Li, Y., Chao, T.M., Chou, R., \& Orban, L. (2002). Novel microsatellites fromAsian sea bass (Lates calcarifer) and their application to broodstock analysis. Marine Biotechnology 4, 503-511.

Citation: MA Zhenhua, , "Mathematical Analysis of Morphometric Attributes Effects on Body Weight of ThreeMonth-Old Lates Calcarifer”. International Journal of Innovative Studies in Aquatic Biology and Fisheries, 5(4), pp.36-41 .http://dx.doi.org/10.20431/2454-7670.0504007

Copyright: () 2019 Authors. This is an open-access article distributed under the terms of the Creative Commons Attribution License, which permits unrestricted use, distribution, and reproduction in any medium, provided the original author and source are credited. 